\title{
AUDIT TATA KELOLA TEKNOLOGI INFORMASI MENGGUNAKAN FRAMEWORK COBIT 5 (Studi Kasus: PT Pelabuhan Indonesia II (Persero) Cabang Panjang)
}

\author{
Adhie Thyo Priandika ${ }^{1}$, Sherly Octavia ${ }^{2}$ \\ ${ }^{1}$ Jurusan Teknologi Informasi, FTIK UniversitasTeknokrat Indonesia, Lampung \\ ${ }^{2}$ Jurusan Sistem Informasi, FTIK UniversitasTeknokrat Indonesia, Lampung \\ Email:*1adhie_thyo@teknokrat.ac.id, ${ }^{2}$ sherlyoktavia31@gmail.com
}

\begin{abstract}
Long Port is one of the ports under management PT Pelabuhan Indonesia II (Persero), a BUMN that is engaged in port and national logistics services. now the long harbor has utilized information technology to support container operational service business processes that will export and import goods in the terminal division by using a VGM (Verified Gross Mass) system that functions to verify the container gross weight. So that the application of information technology can be used optimally, we need a governance that is commonly called information technology governance. Information technology governance is part of corporate governance that focuses on information technology systems and as well as performance and risk management. One of the standards used in information technology governance is COBIT (Control Objectives for Information and Related Technology). This research was conducted using a scale measuring maturity level maturity level, stages carried out using COBIT 5 Implementation up to stage 4 - Plan Program, calculations using statistical averages or means in the form of a total value of various items in each questionnaire. The APO08 process will be used as a process to find out how the relation of the level of maturity of the application of the VGM (Verified Gross Mass) system in supporting business processes to provide container operational services at the Panjang port..
\end{abstract}

Keyword : Audit, Information Technology Governance, Maturity Level, COBIT 5, APOO8

\begin{abstract}
Abstrak
Pelabuhan Panjang merupakan salah satu pelabuhan yang berada di bawah pengelolaan manajemen PT Pelabuhan Indonesia II (Persero), sebuah BUMN yang bergerak di bidang jasa kepelabuhanan dan logistik nasional. kini pelabuhan panjang telah memanfaatkan teknologi informasi untuk mendukung proses bisnis pelayanan operasional petikemas yang akan melakukan eksport-import barang pada divisi terminal yaitu dengan menggunakan sistem VGM (Verified Gross Mass) yang berfungsi untuk memverifikasi berat kotor petikemas. Agar penerapan teknologi informasi dapat digunakan secara optimal, diperlukan suatu tata kelola yang biasa disebut tata kelola teknologi informasi. Tata kelola teknologi informasi adalah bagian dari tata kelola perusahaan yang menitikberatkan pada sistem dan teknologi informasi serta manajemen kinerja dan risiko. Salah satu standar yang digunakan dalam tata kelola teknologi informasi adalah COBIT (Control Objectives for Information and Related Technology). Penelitian ini dilakukan dengan menggunakan skala pengukuran tingkat kematangan maturity level, tahapan yang dilakukan menggunakan COBIT 5 Implementation sampai pada tahap 4 - Plan Programme, perhitungan menggunakan rata-rata statistik atau mean berupa total nilai dari berbagai item dalam setiap kuesioner. Proses APO08 akan digunakan sebagai proses untuk mengetahui bagaimana relasi tingkat kematangan dari penerapan sistem VGM (Verified Gross Mass) dalam mendukung proses bisnis untuk memberikan pelayanan operasional petikemas pada Pelabuhan Panjang.
\end{abstract}

Kata kunci : Audit, Tata Kelola Teknologi Informasi, Maturity Level, COBIT 5, APOO8.

\section{Pendahuluan}

Saat ini teknologi informasi (TI) menjadi suatu bagian yang sangat penting bagi organisasi perusahaan karena dipercaya dapat membantu meningkatkan efektifitas dan efisiensi proses bisnis perusahaan. Perusahaan menempatkan teknologi sebagai suatu hal yang dapat mendukung pencapaian visi, misi dan tujuan perusahaan. Perusahaan tersebut berupaya untuk menerapkan suatu sistem informasi yang dapat memenuhi kebutuhan perusahaan dalam mencapai tujuan misalnya untuk meningkatkan kegiatan operasional kerja. Pelabuhan Panjang merupakan salah satu pelabuhan yang berada di bawah pengelolaan manajemen PT Pelabuhan Indonesia II (Persero), sebuah BUMN yang bergerak di bidang jasa kepelabuhanan dan logistik nasional. Kini pelabuhan panjang telah memanfaatkan teknologi informasi untuk 
mendukung proses bisnis pelayanan operasional petikemas yang akan melakukan eksport-import barang pada divisi terminal yaitu dengan menggunakan sistem VGM (Verified Gross Mass) yang berfungsi untuk memverifikasi berat kotor petikemas. Verifikasi berat kotor petikemas sangat dibutuhkan dalam penyusunan petikemas di atas kapal, sehingga keseimbangan dan keselamatan kapal serta barang dapat lebih terjamin. Agar penerapan teknologi informasi dapat digunakan secara optimal, diperlukan suatu tata kelola yang biasa disebut tata kelola teknologi informasi. Tata kelola teknologi informasi adalah bagian dari tata kelola perusahaan yang menitikberatkan pada sistem dan teknologi informasi serta manajemen kinerja dan risiko. Salah satu standar yang digunakan dalam tata kelola teknologi informasi adalah COBIT (Control Objectives for Information and Related Technology).

Pelabuhan Indonesia Cabang Panjang menyadari pentingnya kegiatan pengelolaan dan evaluasi teknologi informasi yang telah diterapkan. Kegiatan tata kelola teknologi informasi saat ini telah dilakukan secara berkala oleh pihak audit internal Pelabuhan Panjang. Namun, belum dilakukan secara maksimal pada penerapan sistem VGM (Verified Gross Mass) yang kini baru diimplementasikan, sehingga belum diketahui tingkat kematangan dari penerapan sistem apakah sudah mendukung proses bisnis dalam memberikan pelayanan operasional pada petikemas. Oleh karena itu, untuk mengetahui tingkat kematangan dari penerapan sistem secara maksimal dalam memberikan pelayanan operasional bisnis diperlukan evaluasi audit tata kelola teknologi informasi.

\section{Telaah pustaka}

\section{A. Audit}

Menurut (Wardani, 2014) Audit pada dasarnya adalah proses sistematis dan obyektif dalam memperoleh dan mengevaluasi bukti-bukti tindakan ekonomi, guna memberikan asersi / pernyataan dan menilai seberapa jauh tindakan ekonomi sudah sesuai dengan kriteria yang berlaku dan mengkomunikasikan hasilnya kepada pihak terkait.

\section{B. Tata Kelola Teknologi Informasi}

\section{Tata Kelola}

Jogiyanto dan Abdillah (2011) menjelaskan tata kelola (governance) merupakan suatu proses yang dilakukan oleh suatu organisasi atau masyarakat untuk mengatasi permasalahan yang terjadi.

2. Teknologi Informasi

Menurut Handayaningsih (2013) Mendefinsikan Teknologi Informasi (Information Technology) adalah hardware dan software, dan bisa termasuk di dalamnya jaringan dan telekomunikasi yang biasanya dalam konteks bisnis atau usaha.

3. Tata Kelola Teknologi Informasi

Handayaningsih (2013) mendefinisikan tata kelola TI yang diambil dari IT Governance Institute adalah :
"Tata kelola TI sebagai tanggungjawab eksekutif dan dewan direksi, sebagai bagian dari tata kelola bisnis terdiri atas kepemimpinan, struktur dan proses-proses organisasi, yang akan memastikan bahwa TI organisasi tersebut bisa mendukung dan menyampaikan tujuan strategis organisasi".

\section{COBIT 5}

ISACA (2012) COBIT 5 (Control Objektives For Information and Related Technology) COBIT 5 mendefinisikan dan menjelaskan secara rinci sejumlah tata kelola dan manajemen proses. COBIT 5 menyediakan kerangka kerja yang komprehensif yang membantu perusahaan dalam mencapai tujuan mereka untuk tata kelola dan manajemen aset informasi perusahaan dan teknologi (TI). Secara sederhana, membantu perusahaan menciptakan nilai yang optimal dari TI dengan menjaga keseimbangan antara mewujudkan manfaat dan mengoptimalkan tingkat resiko dan penggunaan sumber daya.

\section{- Prinsip Dasar COBIT 5}

Berikut adalah gambar 1 adalah 5 prinsip framework COBIT.

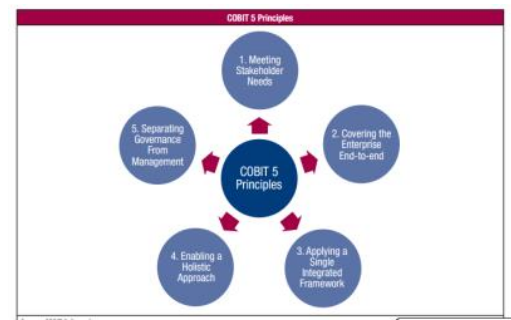

Gambar 1 Prinsip Dasar COBIT 5 (ISACA, 2012)

\section{Pemetaan Balanced Scorecard COBIT 5}

Apabila diartikan secara sederhana dengan kamus bahasa, Balanced berarti keseimbangan, Scorecard berarti kartu nilai, dapat diartikan sebuah kartu nilai untuk menghasilkan sesuatu keseimbangan bergantung pada apa yang dinilai. Menurut (Sarno, 2009) COBIT mendefinisikan tujuan bisnis terkait dengan aktivitas teknologi informasi yang umumnya ada diperusahaan. Pada karangka kerja COBIT hanya menjelaskan tujuantujuan yang berkaitan dengan TI. Pada gambar dibawah ini dijelaskan langkah-langkah dalam menentukan proses domain.

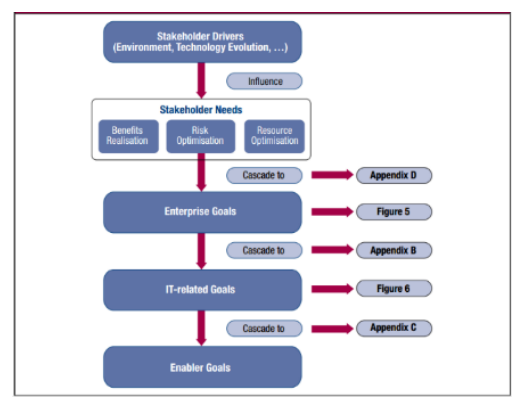

Gambar 2. COBIT 5 Goals Cascade Overview (ISACA, 2012) 


\section{E. Metode Penerapan Tata Kelola Teknologi Informasi}

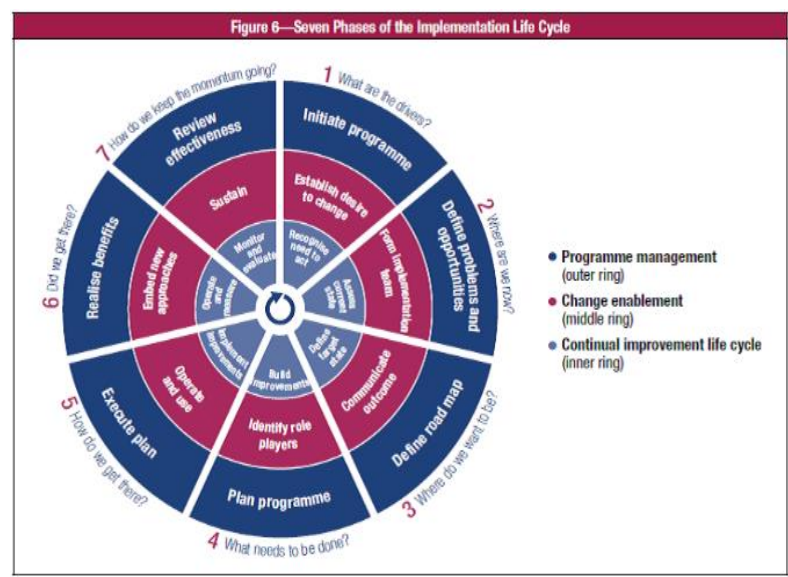

Gambar 3. COBIT 5 Implementation

(ISACA, 2012)

\section{Tahap 1 - Initiate Programme}

Pada tahap ini menjelaskan tentang penggerak pada organisasi dan identifikasi pendorong perubahan saat ini. Tujuannya adalah memperoleh pemahaman tentang organisasi yang berdiri dari tujuan, visi dan misi, pendekatan pengelolaan saat ini dan konsep program organisasi

\section{Tahap 2 - Define Problems and Opportunities}

Pada tahap ini menjelaskan tentang posisi organisasi saat ini (as is) yang berhubungan dengan TI. Manajemen perlu mengetahui kemampuan organisasi saat ini dan dimana kekurangan organisasi. Hal ini dicapai dengan penilaian kemampuan proses terhadap status proses yang dipilih. COBIT 5 menyediakan panduan pemetaan tujuan perusahaan terhadap tujuan TI dan proses TI. Dasar kemampuan organisasi saat ini didapatkan dari hasil kuesioner model maturity level. Dasar organisasi saat ini merupakan acuan untuk melakukan peningkatan atau perbaikan pada kemampuan organisasi saat ini dalam pengelolaan TI.

\section{Tahap 3 - Define Road Map}

Pada tahap ini menjelaskan target perbaikan yang akan dilakukan organisasi dan analisis selisih (gap) untuk mengidentifikasi solusi potensial. Tujuannya adalah untuk menetapkan target kemampuan untuk proses yang dipilih. Road Map adalah arahan bagi organisasi yang digambarkan dengan jalur-jalur pengembangan untuk mencapai tujuan pengembangan aplikasi pada organisasi. Road Map digunakan untuk memastikan pengguna TI benar-benar mendukung tujuan organisasi. GAP adalah metode untuk membandingkan kinerja nyata dengan potensi kerja [13]. GAP didapatkan dari hasil analisa kekampuan organisasi saat ini (as is) yang didapatkan dari hasil kuesioner model maturity level dengan target yang diharapkan (to be).

\section{Tahap 4-Plan Programme}

Pada tahap ini menjelaskan tentang apa yang harus dilakukan organisasi yang berupa solusi perbaikan dan rekomendasi. Tujuan tahap ini menerjemahkan kesempatan memeperbaiki proses yang dipilih.

\section{F. Pengukuran Model Kematangan (Maturity Level)}

Merupakan model kematangan untuk mengontrol prose-proses teknologi informasi dengan menggunakan metode penilaian / scoring, tujuan maturity model adalah antara lain:

a. Organisasi dapat mengetahui posisi kematangan teknologi informasi pada saat ini.

b. Organisasi secara terus menerus dan berkesinambungan harus berusaha untuk meningkatkan levelnya sampai tingkat tertinggi agar aspek governance terhadap teknologi informasi dapat berjalan secara efektif. Tingkat kematangan yang digunakan untuk penilaian pada Maturity Model yaitu skala 0 sampai 5.

\section{Metodologi Penelitian}

Hasil pembahasan ini menggunakan metode pengumpulan data yaitu pengamatan, wawancara, tinjauan pustaka, dan dokumentasi.

\section{A. Kerangka Penelitian}

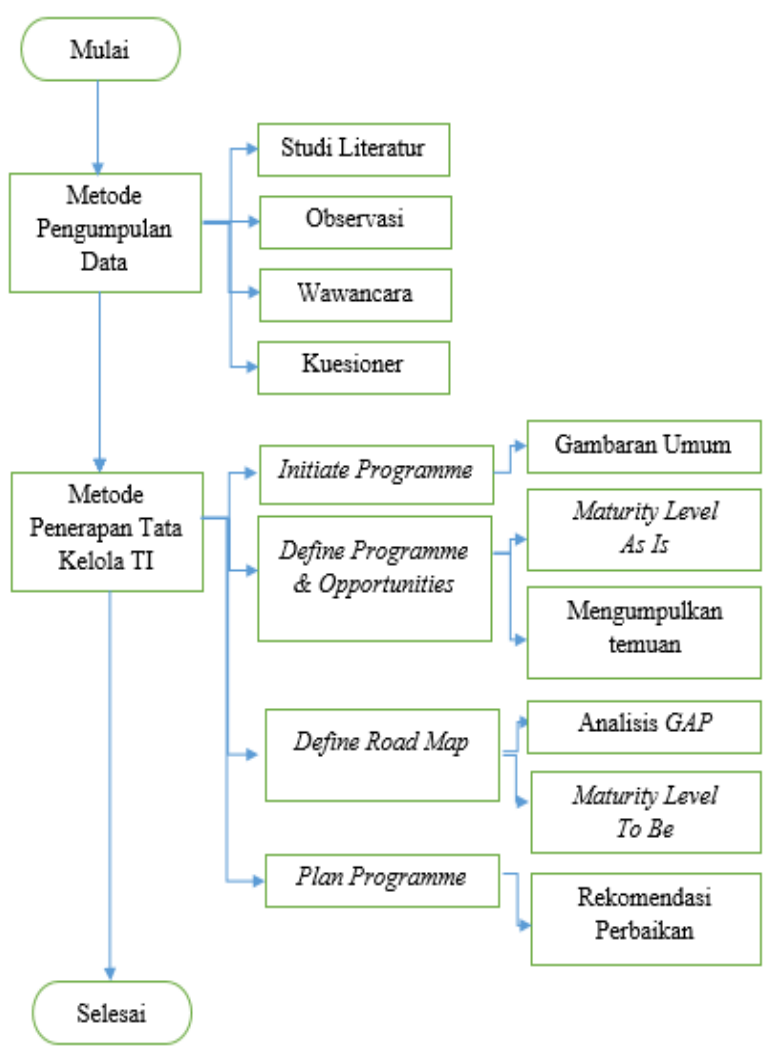

Gambar 4. Kerangka Penelitian 


\section{B. Tahapan Penelitian}

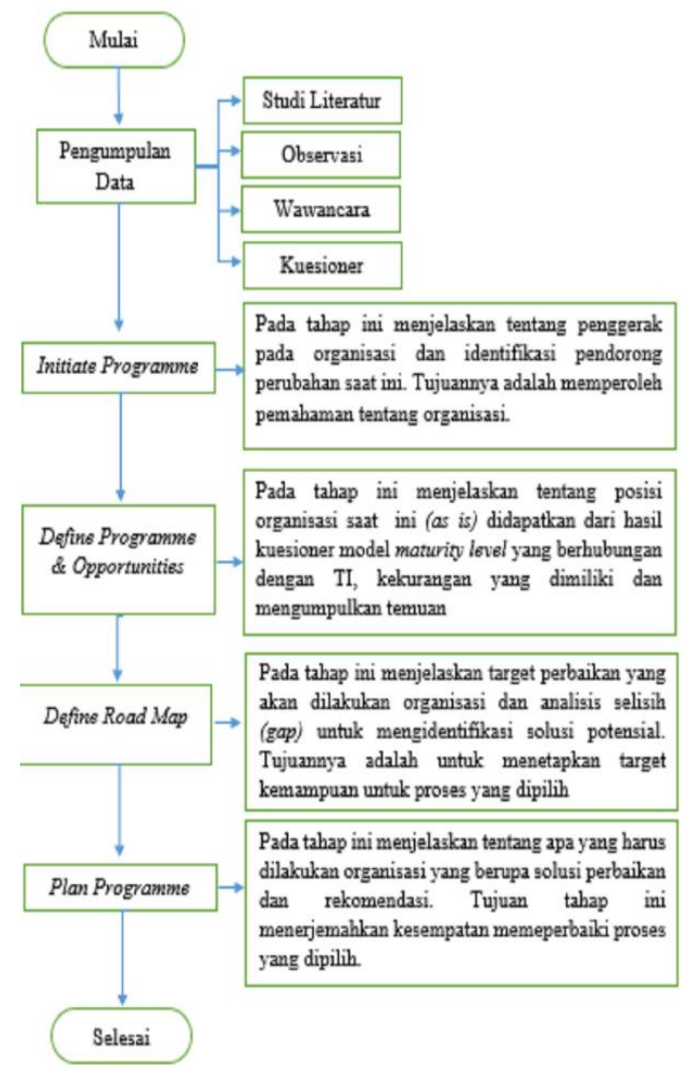

Gambar 5. Tahapan Penelitian

\section{Metode Pengumpulan Data}

1. Data primer diperoleh langsung di lapangan ketika peneliti melakukan observasi, wawancara dan pemberian kuesioner ke PT PELINDO II (Persero) Cabang Panjang.

2. Data sekunder diperoleh dari kajian pustaka yang berhubungan dengan tata kelola teknologi informasi

\section{Analisis Data}

Penelitian ini menggunakan teknik analisis data deskriptif kualitatif yang menekankan pada sumber data dan fakta. Sumber data dijelaskan pada bagian 3.3 metode pengumpulan data dengan dua sumber data yaiutu data primer dan data sekunder. berdasarkan data yang sudah dikumpulkan tersebut melalui observasi, wawancara, kuesioner dan studi literatur maka tahapan selanjutnya adalah data tersebut dianalisis untuk dikembangkan lagi. Seluruh data yang diperoleh di PT Pelabuhan Indonesia II Cabang Panjang dianalisis menggunakan model kematangan (maturity level).

\section{E. Analisis Perhitungan}

Perhitungan dilakukan berdasarkan hasil kuesioner yang dibagian ke karyawan dan pegawai pada PT Pelabuhan Indonesia II (Persero) Cabang Panjang. Perhitungan menggunakan rata-rata statistik atau mean berupa total nilai dari berbagai item dalam setiap kuesioner yang dibagi dengan jumlah total item kuesioner.
Perhitungan dapat dikerjakan dengan rumus dibawah ini :

$$
\text { Mean atau } \bar{\chi}=\frac{\sum X_{\mathrm{i}}}{n}=\frac{X_{1}+X_{2}+\ldots+X_{\mathrm{n}}}{n}
$$

Keterangan

$$
\begin{aligned}
\bar{x} & =\text { Rata }- \text { rata hitung } \\
\Sigma & =\text { Penjumlahan keseluruhan } \\
X_{\mathrm{i}} & =\text { Nilai berapa jumlah } \mathrm{x}, \mathrm{i}=1,2, \ldots, \mathrm{n} \\
n & =\text { Jumlah Sample }
\end{aligned}
$$

\section{F. Identifikasi Domain dan Proses COBIT 5}

Dari proses mapping COBIT 5 dan tujuan terkaita teknologi informasi dapat disimpulkan domain dan proses COBIT 5 yang akan digunakan yaitu APO08 (Manage Relationship). Proses ini menjelaskan tentang pengelolaan hubungan bisnis dengan TI yang fokus pada tujuan perusahaan. Pada penelitian ini, proses APO08 akan digunakan sebagai proses untuk mengetahui bagaimana relasi tingkat kematangan dari penerapan sistem VGM (Verified Gross Mass) dalam mendukung proses bisnis untuk memberikan pelayanan operasional petikemas. Proses dan tujuan pada tabel 1

\section{Tabel 1. Daftar Proses COBIT 5}

\begin{tabular}{|c|l|l|}
\hline Proses & \multicolumn{1}{|c|}{ Indikator } & \multicolumn{1}{c|}{ Tujuan } \\
\hline \multirow{5}{*}{$\begin{array}{c}\text { APO08.01 } \\
\text { Memahami Harapan } \\
\text { Bisnis }\end{array}$} & $\begin{array}{l}\text { Memahami isu-isu bisnis saat ini dan } \\
\text { tujuan harapan bisnis TI }\end{array}$ \\
\cline { 2 - 3 } Hubungan & $\begin{array}{l}\text { APO08.02 } \\
\text { Mengidentifikasi } \\
\text { Peluang, Risiko Dan } \\
\text { Kendala TI Untuk } \\
\text { Meningkatkan Bisnis }\end{array}$ & $\begin{array}{l}\text { Mengidentifikasi peluang potensial } \\
\text { bagi TI untuk meningkatkan kinerja } \\
\text { perusahaan }\end{array}$ \\
\cline { 2 - 3 } & $\begin{array}{l}\text { APO08.03 } \\
\text { Mengelola Hubungan } \\
\text { Bisnis }\end{array}$ & $\begin{array}{l}\text { Mengelola hubungan bisnis dengan } \\
\text { stakeholder }\end{array}$ \\
\cline { 2 - 3 } & $\begin{array}{l}\text { APO08.04 } \\
\text { Koordinasi dan } \\
\text { Komunikasi }\end{array}$ & $\begin{array}{l}\text { Bekerja dengan para pemangku } \\
\text { kepentingan dengan } \\
\text { mengkoordinasikan end to end } \\
\text { pengiriman layanan TI dan solusi } \\
\text { yang diberikan }\end{array}$ \\
\cline { 2 - 3 } & & $\begin{array}{l}\text { Meningkatkan dan mengembangkan } \\
\text { layanan teknologi informasi }\end{array}$ \\
\cline { 2 - 3 } & $\begin{array}{l}\text { APO08.05 } \\
\text { Memberikan Masukan } \\
\text { Untuk Perbaikan } \\
\text { Berkelanjutan Dari } \\
\text { Pelayanan }\end{array}$ & \\
\hline
\end{tabular}

\section{Hasil Dan Pembahasan}

\section{A. Tahap 1 - Initiate Programme}

Langkah pertama dalam melakukan pengelolaan terhadap teknologi informasi pada PT Pelabuhan Indonesia II (Persero) Cabang Panjang adalah mengidentifikasi penggerak atau pendorong pada organisasi. Penggerak pada organisasi tersebut dijelaskan pada gambaran umum tentang perusahaan. Tujuannya adalah memperoleh pemahaman tentang perusahaan secara terperinci yang meliputi struktur organisasi, tujuan, visi dan misi.

\section{B. Tahap 2 - Define Problems and Opportunities - Perhitungan Maturity Level}


Tabel 2. Daftar Hasil Perhitungan Maturity Level

\begin{tabular}{clc} 
Proses & \multicolumn{1}{c}{ Keterangan } & $\begin{array}{c}\text { Maturity } \\
\text { As Is }\end{array}$ \\
\hline APO08.01 & $\begin{array}{l}\text { Memahami harapan } \\
\text { bisnis }\end{array}$ & 4,9 \\
& $\begin{array}{l}\text { Mengidentifikasi } \\
\text { peluang, risiko dan } \\
\text { kendala TI untuk } \\
\text { meningkatkan bisnis }\end{array}$ & 4,8 \\
\hline APO08.03 & $\begin{array}{l}\text { Mengelola hubungan } \\
\text { bisnis }\end{array}$ & 4,8 \\
\hline APO08.04 & $\begin{array}{l}\text { Koordinasi dan } \\
\text { komunikasi }\end{array}$ & 4,9 \\
\hline APO08.05 & $\begin{array}{l}\text { Memberikan masukan } \\
\text { untuk perbaikan } \\
\text { berkelanjutan dari } \\
\text { pelayanan }\end{array}$ & 4,9 \\
\hline APO08 & $\begin{array}{l}\text { Mengelola hubungan } \\
\text { APlan }\end{array}$
\end{tabular}

Berdasarkan data rekapitulasi diatas, hasil perhitungan maturity level dapat disimpulkan bahwa Tingkat kematangan maturity level saat ini pada domain APO08 (Manage Relationship) proses APO08.01, APO08.02, APO08.03, APO08.04 dan APO08.05 adalah level 4 (Managed and Measurable) yang berarti penerapan teknologi informasi telah memiliki ukuran dan sudah dijadikan sasaran maupun obyektifitas kinerja perusahaan. Secara umum tingkat kematangan perusahaan dalam mengelola teknologi informasi sudah mengacu pada level best practice.

\section{- Pengumpulan Hasil Temuan}

a. Hasil Temuan Pada APO08.01 (Memahami Harapan Bisnis)

Pelabuhan Panjang mengadaptasi proses dan teknologi yang sesuai dengan standar kualitas internasional. Secara berkelanjutan memonitor, mengevaluasi serta menyempurnakan proses bisnis untuk memberikan pelayanan yang terbaik.

b. Hasil Temuan Pada APO08.02 (Mengidentifikasi Peluang, Risiko dan Kendala TI untuk Meningkatkan Bisnis)

Adanya pengembangan proses manajemen risiko di perusahaan. Tujuan utama manajemen risiko adalah untuk memitigasi dampak negatif risiko terhadap perusahaan melalui proses pemantauan yang akurat dan perumusan langkah-langkah pencegahan. Objek risiko operasional mencakup kegiatan yang berkaitan langsung dengan proses bisnis pokok kepelabuhanan yang terukur dalam sasaran mutu dan KPI tahun 2015 yaitu pada proses: perencanaan, dan pengendalian operasi, pelayanan barang non petikemas, pelayanan petikemas, pelayanan ruparupa usaha, serta dukungan teknik. Adanya pemahaman bahwa bisnis dan teknologi informasi mendukung tujuan perusahaan sesuai dengan Peraturan Menteri BUMN Nomor: PER-
02/MBU/2013 tentang Panduan Penyusunan Pengelolaan Teknologi Informasi BUMN untuk memastikan iniastif IT selaras dengan bisnis perusahaan serta sebagai acuan untuk pengembangan teknologi informasi selanjutnya terkait arsitektur data atau informasi, infrastruktur dan aplikasi.

c. Hasil Temuan Pada APO08.03 (Mengelola Hubungan Bisnis)

Sebagai wujud kepatuhan terhadap program Good Corporate Governance, manajemen PT Pelabuhan Indonesia II (Persero) Cabang Panjang membuka akses seluas-luasnya kepada seluruh pemangku kepentingan (stakehoder) perusahaan maupun masyarakat umum yang ingin mengetahui berbagai hal seputar Pelabuhan Panjang dengan mengakses beberapa media informasi yang telah disediakan, diantaranya seperti: website, media sosia, sms gateway, dan email. Adanya kegiatan memberikan penghargaan kepada kepada seluruh stakeholder kepelabuhanan seperti pemilik barang, para agen kapal, perusahaan bongkar-muat, dan lainnya, yang selama ini dianggap telah memberikan kontribusi signifikan kepada perusahaan

d. Hasil Temuan Pada APO08.04 (Koordinasi dan Komunikasi)

Adanya proses komunikasi layanan TI. Untuk membangun komunikasi dua arah dengan pelanggan dan sekaligus untuk meningkatkan mutu layanan kepada pengguna jasa, manajemen PT Pelabuhan Indonesia II (Persero) Cabang Panjang telah melakukan berbagai hal, diantaranya adalah: membuka layanan pengaduan pelanggan melalui beberapa saluran, yakni melalui mekanisme rapat pertemuan yang diselenggarakan setiap hari Selasa dan Kamis, surat, email, website, kotak saran di loket-loket pelayanan, dan SMS baik dari cargo owner maupun pihak agen kapal, dimana semua keluhan pelanggan yang masuk diterima dengan baik, dicatat dan segera direspon atau ditindaklanjuti agar keluhan serupa tidak terulang kembali. Adanya langkah khusus untuk seluruh cabang pelabuhan dalam pelayanan jaringan, yaitu telah dilengkapi dengan jaringan backup menggunakan provider nonTelkom untuk mengantisipasi apabila jaringan utama bermasalah.

c. Hasil Temuan Pada APO08.05 (Memberikan Masukan untuk Perbaikan Berkelanjutan dari Pelayanan)

Adanya proses melakukan analisis kepuasan pelanggan. Untuk mendapatkan umpan balik dari para pelanggan guna meningkatkan kualitas layanan yang dihasilkan, setiap tahun manajemen PT Pelabuhan Indonesia II (Persero) Cabang Panjang melaksanakan Survey Kepuasan Pelanggan. Survey dilakukan dengan melibatkan konsultan independen yang kompeten. 


\section{Tahap Define Road Map}

Berikut merupakan diagram hasil pencapaian maturity level pada domain APO08 (Manage Relationship).

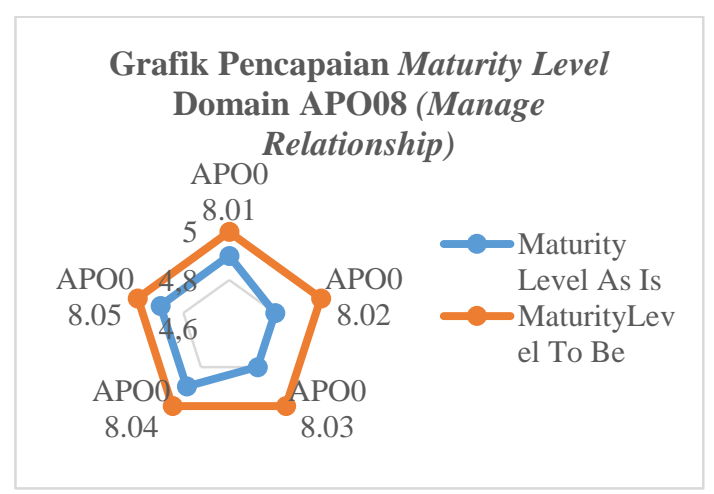

Gambar 6. Grafik Pencapaian Maturity Level Pada Domain APO08

\section{- Analisa GAP}

a. Analisa Gap Pada APO08.01 (Memahami Harapan Bisnis)

Tabel 4.2 Gap Maturity Level Proses APO08.01 Proses Gap Maturity Level

APO08.01 Kegiatan perencanaan, monitoring dan penyesuaian pengembangan teknologi informasi terhadap proses bisnis sudah dilakukan secara berkala. Namun belum dilakukan secara maksimal pada penerapan sistem VGM (Verified Gross Mass) yang kini baru diimplementasikan pada terminal petikemas Pelabuhan Panjang.

Divisi sistem informasi belum
melakukan rencana analisis untuk mengetahui isu-isu pemanfaatan teknologi saat ini, khususnya pada sistem VGM (Verified Gross Mass).

Belum adanya upaya mengoptimalkan pengembangan layanan TI terhadap bisnis proses.

b. Analisa Gap Pada APO08.02 (Mengidentifikasi Peluang, Risiko dan Kendala Teknologi Informasi untuk Meningkatkan Bisnis)

Tabel 4.3 Gap Maturity Level Proses APO08.02 Proses Gap Maturity Level

APO08.02 Belum optimalnya sistem manajemen risiko dan sistem pengendalian internal.

c. Analisa Gap Pada APO08.03 (Mengelola Hubungan Bisnis)

Tabel 4.4 Gap Maturity Level Proses APO08.03 Proses Gap Maturity Level

APO08.03 Terus meningkatkan program Good Corporate Governance agar proses dan mekanisme dalam menjalankan operasional dan proses bisnis perusahaan dapat terlaksana dengan baik.

d. Analisa Gap Pada APO08.04 (Koordinasi dan Komunikasi)

Tabel 4.5 Gap Maturity Level Proses APO08.04

Proses Gap Maturity Level

APO08.04 Belum adanya komunikasi khusus
secara terarah dalam pengelolaan masalah TI.

Penerapan aplikasi helpdesk belum terakomodir pada sistem VGM (Verified Gross Mass).

e. Analisa Gap Pada APO08.05 (Memberikan Masukan untuk Perbaikan Berkelanjutan dari Pelayanan)

Tabel 4.6 Gap Maturity Level Proses APO08.05 Proses Gap Maturity Level

APO08.05 Pelabuhan panjang belum secara optimal membangun struktur organisasi dan kedudukan divisi audit untuk mengawasi kepatuhan internal, manajemen risiko dan jaminan mutu.

Belum adanya pelaporan pelanggaran baik dari pihak internal maupun eksternal dalam melengkapi sistem pengendalian internal.

Belum adanya prosedur khusus yang tersktruktur dalam pengelolaan layanan TI.

\section{Tahap 4 - Plan Programme}

- Rekomendasi Perbaikan

a. Rekomendasi Perbaikan APO08.01 (Memahami Harapan Bisnis)

Terus melakukan transformasi terhadap kelangsungan layanan TI dengan mempertahankan informasi yang up to date, serta memenuhi standar prosedur pengelolaan TI yang sesuai dengan kebijakan dan kebutuhan tujuan perusahaan. Divisi teknik dan sistem informasi mengembangkan IT Governance untuk meningkatkan layanan TI dalam bisnis proses maupun back office sebagai upaya mengoptimalkan Information and Technology General Control (ITGC).

b. Rekomendasi Perbaikan APO08.02 (Mengidentifikasi Peluang, Risiko dan Kendala Teknologi Informasi untuk Meningkatkan Bisnis)

Mengoptimalkan pengelolaan Sistem Pengendalian Internal dan manajemen risiko berdasarkan kerangka acuan Sistem Pengendalian Internal Perseroan Pasal 26 Peraturan Menteri Negara BUMN No. PER01/2011 tentang Penerapan Praktik Good Corporate 
Governance pada BUMN. Memperkuat sistem pengendalian internal melalui: a) Penyempurnaan struktur organisasi yang mencakup pemisah tugas dan wewenang, kebijakan, penerapan sistem dan prosedur operasi, b) Penerapan enterprise risk management, risiko-risiko utama dan strategis telah diidentifikasi, dipetakan, dan dikelola secara memadai, c) Implementasi Information and Communication Technology (ICT) yang mencakup seluruh aktivitas perseroan hingga pelaporan, d) Proses monitoring dan evaluasi dilakukan oleh atasan langsung.

c. Rekomendasi Perbaikan APO08.03 (Mengelola Hubungan Bisnis)

Terus meningkatkan program tanggung jawab sosial perusahaan (Corporate Social Responsibility) yang bermanfaat, berkesinambungan dan dapat dirasakan efek positifnya dalam mengelola hubungan dengan masyarakat. Mulai memfokuskan program komunikasi pemasaran terhadap keunggulankeunggulan yang dimiliki oleh Pelabuhan Panjang baik itu fasilitas, peralatan, maupun pelayanan dengan mengoptimalkan penggunaan media massa khususnya media elektronik dan media cetak.

d. Rekomendasi Perbaikan APO08.04 (Koordinasi dan Komunikasi)

Membangun Centralized IT Service Support yang berfungsi sebagai IT Helpdesk untuk melayani keluhan dan gangguan layanan IT diseluruh cabang.

c. Rekomendasi Perbaikan APO08.05 (Memberikan Masukan untuk Perbaikan Berkelanjutan dari Pelayanan)

Melakukan penataan data customer melalui program Customer Data Management, Customer Data Management selain bermanfaat untuk mengelola data customer, diharapkan juga bermanfaat untuk mendukung rencana perusahaan menerapkan sistem Customer Relationship Management. Penerapan sistem Customer Relationship Management pada perusahaan nantinya diharapkan bermanfaat bagi perusahaan untuk memahami kebutuhan pada customer dan juga meningkatkan respon perusahaan terhadap kebutuhan customer. Untuk melengkapi keseluruhan sistem pengendalian internal dan pelaksanaan tata kelola yang baik, perusahaan dapat mengembangkan ssebuah sistem untuk mengelola pelaporan kecurangan, pelanggaran serta indikasi jika adanya perilaku yang tidak benar, tidak etis atau ilegal. Menyusun dan menerapkan framework untuk pengembangan Software Development Life Cycle (SDLC) dan kebijakan pengelolaan sistem informasi sebagai tindak lanjut laporan audit sistem informasi. Menyempurnakan seluruh bisnis model pelayanan kapal dan barang sebagai upaya meningkatkan kualitas pelayanan dan mengefektifkan pengendalian internal termasuk diantaranya menerapkan sistem aplikasi untuk terminal petikemas, sistem pergudangan, pengelolaan lapangan, demaga, armada dan sebagainya.

\section{Simpulan}

Tingkat kematangan maturity level saat ini pada domain APO08 (Manage Relationship) adalah level 4 (Managed and Measurable) yang berarti penerapan teknologi informasi telah memiliki ukuran dan sudah dijadikan sebagai sasaran maupun obyektifitas kinerja perusahaan. Secara umum tingkat kematangan perusahaan dalam mengelola teknologi informasi sudah mengacu pada level best practice. Perhitungan maturity level didapatkan dari rekapitulasi hasil jawaban kuesioner maturity level. Perhitungan menggunakan rata-rata statistik atau mean dari berbagai item dalam setiap kuesioner pada domain APO08 (Manage Relationship) dengan nilai rata-rata tingkat kematangan saat ini (maturity level as is) adalah 4,9. Sedangkan target tingkat kematangan yang diharpakan perusahaan (maturity level to be) adalah 5, sehinggan adanya gap sebesar 0.1 .

\section{Referensi}

[1] Nugroho, R., Suryono, R., Darwis, D. “Audit Tata Kelola Teknologi Informasi Untuk Integritas Data Menggunakan Framework Cobit 5 pada PT Kereta Api Indonesia (Persero) Divre IV TNK'. Jurnal TEKNOINFO. Vol. 10, No.1, 2016, 1-6. 2016.

[2] ISACA. COBIT 5 A Business Framework for the Governance and Management of Enterprise IT.USA: IT Governance Institute. 2012

[3] ISACA. 2012. COBIT 5 Enabling Process.USA: IT Governance Institute.

[4] ISACA. 2012. COBIT 5 Enabling Information.USA: IT Governance Institute.

[5] ISACA. 2012. COBIT 5 Implementation.USA: IT Governance Institute.

[6] Jogiyanto, H.M. \& Abdillah, W. 2011. Sistem Tata Kelola Teknologi Informasi. Yogyakarta:ANDI.

[7] Khotari, C.R. 2004. Research Methodology Methods and Techniques Second. New Delhi: New Age Publisher.

[8] Sanjaya, Wina. 2013. Pelelitian Pendidikan: Jenis, Metode dan Prosedur. Jakarta: Kharisma Putra Utama.

[9] Sarno, Riyanto. 2009. Audit Sistem dan Teknologi Informasi. Surabaya: ITSpers.

[10] Sugiyono. 2012. Memahami Penelitian Kualitatif. Bandung: ALFABETA.

[11] Suryono,R., Darwis, D. Gunawan, S. "Audit Tata Kelola Teknologi Informasi Menggunakan Framework Cobit 5 (Studi Kasus: Balai Besar Perikanan Budidaya Laut Lampung)". Jurnal TEKNOINFO. Vol. 12, No.1, 2018, 16-22. 2018.

[12] Surendro, K. 2009. Implementasi Tata Kelola Teknologi Informasi. Bandung: Informatika.

[13] Wakhinuddin. 2009. Analisa Gap. Dikutip pada 10 Mei 2017. 